\title{
La Enseñanza del álgebra en los años iniciales de la Enseñanza Fundamental: Investigaciones y orientaciones curriculares
}

\author{
Claudianny Amorim Noronha ${ }^{1}$ \\ cnoronha.ufrn@gmail.com \\ https://orcid.org/0000-0002-4238-065X \\ Luanna Priscila da Silva Gomes ${ }^{1}$ \\ luanna.gomes1@gmail.com \\ https://orcid.org/0000-0002-7157-6870 \\ ${ }^{1}$ Universidade Federal do Rio Grande do Norte
}

Recibido: 05/05/2020 Aceptado: 30/05/2020

\begin{abstract}
Resumen
El objetivo de del estudio reportado en este artículo fue investigar las orientaciones para la enseñanza y el aprendizaje del álgebra en los años iniciales de la Enseñanza Fundamental contenidas en los documentos curriculares oficiales que orienta las prácticas pedagógica en la Educación Básica, así como también hacer un inventario de los estudios sobre el tema, divulgados en las memorias de uno de los principales eventos brasileros de Educación Matemática. Para ello, fueron utilizados elementos propios de las pesquisas de tipo documental y bibliográfica. La investigación permitió realizar un mapeo general de la caracterización acerca de la enseñanza y el aprendizaje del álgebra con infantes, y constatar que ese eje de la matemática, para los años iniciales de la Enseñanza Fundamental, debe ser diseminado, mejor explorado, investigado y comprendido tanto en sus aspectos teóricos y metodológicos.

Palabras clave: enseñanza del álgebra, orientaciones curriculares, años iniciales de la Enseñanza Fundamental

\section{O ensino de álgebra nos anos iniciais do Ensino Fundamental: pesquisas e orientações curriculares}

\section{Resumo}

O presente artigo objetiva investigar orientações acerca do ensino e aprendizagem da álgebra nos anos iniciais do Ensino Fundamental em documentos oficiais curriculares brasileiros que apresentam direcionamentos para práticas pedagógicas na Educação Básica, bem como inventariar pesquisas sobre o tema, divulgadas nos anais de um dos principais eventos brasileiros de Educação Matemática. Para isso, foram utilizados elementos das pesquisas documental e bibliográfica. A investigação possibilitou um mapeamento geral sobre o ensino e aprendizagem da álgebra com crianças e a constatação de que esse eixo da matemática, para os anos iniciais do Ensino Fundamental, necessita ser disseminado, melhor explorado, investigado e compreendido em seus aspectos teóricos e metodológicos.

Palavras-chave: ensino de álgebra, orientações curriculares, anos iniciais do Ensino Fundamental 
O ensino de álgebra nos anos iniciais do Ensino Fundamental...

\title{
The teaching of algebra in the initial years of elementary school: research and curricular guidelines
}

\begin{abstract}
This paper aims to investigate guidelines about teaching and learning algebra in the initial years of Elementary Education in official Brazilian curricular documents, which presents guidelines for pedagogical practices in Basic Education, as well as to inventory research on the theme, published in the annals of one of the main Brazilian events of Mathematical Education. For this, elements of documentary and bibliographic research were used. The investigation enabled a general mapping about teaching and learning algebra with children and the finding that this axis of mathematics, for the early years of elementary school, needs to be disseminated, better explored, investigated and understood in its theoretical and methodological aspects.
\end{abstract}

Keywords: algebra teaching, curriculum guidelines, initial years of elementary school

\section{Introdução}

O documento normativo do Ministério da Educação brasileiro, denominado Base Nacional Comum Curricular - BNCC (BRASIL, 2017), aprovado pelo Conselho Nacional de Educação - CNE brasileiro, em 2017, acarretou, entre outras, uma demanda sistemática quanto ao ensino e a aprendizagem da álgebra, uma vez que o documento apresenta esse conhecimento matemático como uma unidade/eixo temático com objetos e habilidades pedagógicas específicas para serem trabalhadas com estudantes desde o $1^{\circ}$ ano do Ensino Fundamental.

Nesse sentido, questionamo-nos sobre qual o diferencial desse documento quanto à abordagem da álgebra nos anos iniciais do Ensino Fundamental em relação a outros antecedentes, com papel semelhante, e quais as perspectivas abordadas em pesquisas da área da Educação Matemática sobre o trabalho desse conteúdo com crianças. Com o intuito de responder a tais questionamentos, apresentamos o resultado deste estudo, cujo enfoque está no ensino e aprendizagem da álgebra nos primeiros cinco anos da Educação Básica.

Neste texto objetivamos investigar orientações acerca do ensino e aprendizagem da álgebra nos anos iniciais do Ensino Fundamental em documentos oficiais curriculares brasileiros, que apresentam direcionamentos para práticas pedagógicas na Educação Básica, bem como inventariar pesquisas sobre o tema, divulgadas nos anais de um dos principais eventos brasileiros de Educação Matemática. Assim, busca-se oferecer um mapeamento geral sobre as demandas curriculares apontadas nesses documentos e os alcances de pesquisas para atendê-las, no que refere ao ensino da álgebra para crianças.

A análise em documentos oficiais brasileiros que apresentam orientações e diretrizes curriculares foi o ponto de partida de nossa investigação, a medida que se desdobram 
diretamente na sala de aula e subsidiam práticas educacionais, considerando as discussões pedagógicas de cada época. As orientações documentais dessa natureza repercutem no perfil do livro didático, no currículo, planejamento, objetivos, formação dos professores e na elaboração do Projeto Político Pedagógico em instituições escolares públicas e privadas.

O levantamento das pesquisas científicas que abordam o ensino e a aprendizagem da álgebra nos anos iniciais, por sua vez, evidenciam abordagens do ensino da álgebra para crianças em pesquisas brasileiras. Tanto para a análise dos documentos, quanto dos trabalhos científicos, optamos em não nos deter em analisar as concepções sobre o pensamento algébrico adotadas, deixando-a para outra oportunidade.

A análise desses documentos considerou aspectos referentes às pesquisas documental e bibliográfica. Ambas na perspectiva adotada por Oliveira (2007 apud SÁ-SILVA, ALMEIDA, GUINDANE, 2009, p. 6), para a qual a primeira corresponde àquelas caracterizadas pela busca de informações em documentos que não receberam nenhum tratamento científico, ou seja, sem tratamento analítico, que na pesquisa ora apresentada são os documentos oficiais de orientação curricular. Na segunda, por sua vez, o pesquisador se ocupa de estudar e analisar documentos de domínio científico, nos quais temos os artigos científicos, a exemplo dos analisados nos anais de eventos. As estratégias de análise dos documentos e artigos de anais tratadas neste estudo são melhor explicitadas nas seções específicas de cada um.

Nesse sentido, o texto apresenta, na seção a seguir, os documentos de orientações curriculares investigados e as justificativas de suas escolhas. Essa seção é composta por três subseções em que são apresentadas as análises de cada um desses documentos: Parâmetros Curriculares Nacionais - PCN de Matemática, dos anos iniciais e finais do Ensino Fundamental; Elementos Conceituais e Metodológicos para a definição dos Direitos de Aprendizagem e desenvolvimento do Ciclo de alfabetização do Ensino Fundamental; BNCC. Após, apresentamos como se deu o levantamento bibliográfico sobre a álgebra nos anos iniciais do Ensino Fundamental nos anais de doze edições do Encontro Nacional de Educação Matemática. Enfim, as Considerações Finais apresentam uma síntese dos resultados apresentados ao longo do texto.

\section{A álgebra nos anos iniciais do Ensino Fundamental: orientações de documentos oficiais}

Realizamos a leitura de documentos orientadores sobre a álgebra no Ensino Fundamental em três ciclos da Educação Básica: $1^{\circ}$ ciclo $\left(1^{\circ}, 2^{\circ}\right.$ e $3^{\circ}$ anos), conhecido como ciclo de 
O ensino de álgebra nos anos iniciais do Ensino Fundamental...

alfabetização e letramento; $2^{\circ}$ ciclo ( $4^{\circ}$ e $5^{\circ}$ anos); e o ciclo final do Ensino Fundamental $\left(6^{\circ}\right.$ ao $9^{\circ}$ ano). Embora esta pesquisa tenha como foco os anos iniciais do Ensino Fundamental $\left(1^{\circ}\right.$ ao $5^{\circ}$ ano), a análise de documentos dos anos finais aconteceu com vistas a mapear as orientações curriculares, suas indicações de continuidades ou possíveis rupturas entre um ciclo e outro.

A análise inicial partiu dos Parâmetros Curriculares Nacionais - PCN de Matemática (BRASIL, 1997) dos anos iniciais do Ensino Fundamental. A análise desse documento se justifica porque os PCN ocuparam um espaço relevante no cenário educacional brasileiro, durante cerca de 20 anos. Suas orientações repercutiram diretamente nas práticas escolares e na formação de professores e orientaram o desenvolvimento de pesquisas em diferentes áreas de conhecimento.

Analisamos também os Parâmetros Curriculares de Matemática dos anos finais do Ensino Fundamental (BRASIL 1998), mas com o objetivo de identificar se as concepções sobre o ensino e a aprendizagem da álgebra nesse documento dialogam ou não com aquele dos anos iniciais do Ensino Fundamental.

Em um segundo momento, a análise se deu sobre o "Elementos conceituais e metodológicos para definição dos direitos de aprendizagem e desenvolvimento do Ciclo de alfabetização ( $1^{\circ}, 2^{\circ}$ e $3^{\circ}$ anos) do Ensino Fundamental” (BRASIL, 2012), em vigência até 2017. Esse documento orientou o planejamento de políticas educacionais e o ensino no ciclo de alfabetização, possibilitando-nos compreender as indicações curriculares quanto ao ensino e a aprendizagem da álgebra para esse período da Educação Básica.

Em seguida, investigamos as indicações da Base Nacional Comum Curricular - BNCC (BRASIL, 2017) para o ensino da álgebra nos anos iniciais do Ensino Fundamental. Esse documento normativo é a principal diretriz de orientação curricular em vigor do Ministério da Educação brasileiro - MEC. O novo documento ainda está em fase de apropriação pelas escolas e instituições formadoras de professores, embora seja alvo de críticas quanto à estratégia adotada para a sua elaboração e às questões curriculares, a exemplo das referentes à relação entre práticas pedagógicas e políticas, o que abrange o tratamento e enfoque dado aos conteúdos de ensino, a concepção de competência adotada, a abordagem de temáticas de interesse de diferentes grupos sociais, dentre outros (CURY, REIS, ZANARDI, 2018). Apesar das discussões, nossa apreciação se justifica pela relevância do documento no cenário nacional e por apresentar uma unidade temática específica sobre a álgebra nos anos iniciais do Ensino Fundamental. 
Apresentamos, nos próximos tópicos, as especificidades dos documentos analisados. Ressaltamos que a leitura dos documentos objetivou o mapeamento investigativo, para conhecermos globalmente as orientações de documentos curriculares oficiais quanto ao ensino e aprendizagem da álgebra nos anos iniciais do Ensino Fundamental.

\section{A álgebra nos Parâmetros Curriculares Nacionais de matemática dos anos iniciais e finais do Ensino Fundamental}

Os PCN apresentam uma série de direcionamentos e objetivos curriculares quanto às diferentes áreas de ensino. É um documento de natureza aberta e flexível, não apresentado como uma imposição, e sim como orientações, indicações ao desenvolvimento de melhorias curriculares para instituições escolares de todo o território brasileiro.

A origem dos PCN se deu a partir da participação do Brasil na Conferência Mundial de Educação para Todos, em 1990. Essa participação se desdobrou em compromissos assumidos na busca pela qualidade da Educação, dentre eles, a elaboração do Plano Decenal Educação para Todos (1993-2003). Um dos objetivos do Plano foi a elaboração de diretrizes curriculares nacionais, indicada na Lei de Diretrizes e Bases da Educação - Lei Federal n. 9394/96 (BRASIL, 1996) e no Artigo 210 da Constituição Federal de 1988 (BRASIL, 1988). Em resposta a essa demanda os PCN são lançados, em 1997, pelo Ministério da Educação brasileiro, passando a vigorar até 2017, quando foi substituído pela BNCC.

Assim, no processo de leitura investigativa dos PCN dos anos iniciais (BRASIL, 1997) e dos anos finais (BRASIL, 1998) do Ensino Fundamental, procuramos palavras-chave como álgebra e/ou algébrico. Para facilitar o procedimento de análise, ao identificarmos essas palavras, selecionamos as citações, copiamos e organizamos em um quadro, construído em um processador de textos. Nesse processo, nos PCN dos anos iniciais, localizamos apenas cinco ocorrências com as palavras-chave álgebra e/ou algébrico. Após a leitura e análise das citações, voltamos ao texto do documento e realizamos a leitura do tópico completo em que a citação selecionada estava inserida.

Identificamos em nossa análise que os PCN de matemática dos anos iniciais apresentam dois principais aspectos ao tratar sobre a álgebra: o primeiro diz respeito ao posicionamento favorável de introdução ao ensino e aprendizagem da álgebra nos anos iniciais, denominado pelo documento como pré-álgebra; o segundo é o fato de que esse documento não apresenta 
orientações e nem objetivos específicos acerca da abordagem do ensino e da aprendizagem da álgebra. Isso acontece porque, de acordo com o documento, o trabalho sistemático com a álgebra deve ser realizado apenas nos anos finais do Ensino Fundamental, demonstrando, assim, um parecer contrário à formalização algébrica com crianças dos anos iniciais, por isso a denominação de pré-álgebra.

Em suma, apesar de demonstrar-se favorável à introdução da álgebra, o documento isenta-se quanto às orientações pedagógicas, detendo-se a mencionar que o trabalho com esse conteúdo deve se dar de modo a estabelecer relações com a geometria, com o estudo dos números e operações e das grandezas e medidas. Os PCN de matemática dos anos iniciais ressaltam que o conhecimento matemático (aritmético, algébrico, estatístico, geométrico, métrico, combinatório e probabilístico) deve ser utilizado para observar, organizar e produzir informações de maneira analítica e crítica (BRASIL, 1997, p. 37).

Embora não exponha orientações específicas acerca de objetivos, conteúdos, abordagens metodológicas e práticas pedagógicas para o trabalho com a álgebra nos anos iniciais do Ensino Fundamental, o posicionamento firmado quanto à necessidade de relacionar a álgebra a outros eixos da matemática, desde os anos iniciais do Ensino Fundamental, torna esse documento um ponto de partida importante para a discussão curricular de ensino e aprendizagem da álgebra nesse nível de ensino.

A partir da análise dos PCN de matemática dos anos iniciais, julgamos necessário investigar também a abordagem trazida no documento de matemática dos anos finais do Ensino Fundamental (BRASIL, 1998). Nessa investigação, buscamos compreender, nas orientações sobre o ensino e aprendizagem da álgebra presentes nesse documento, possíveis relações com aqueles analisadas no documento dos anos iniciais, a medida que se tratava de um continuidade da formação escolar.

A análise nos permitiu concluir que os PCN dos anos finais do Ensino Fundamental (BRASIL, 1998) fomentam a reflexão sobre o ensino e aprendizagem da álgebra, de modo mais sistemático que o documento que orienta o ciclo e formação anterior. Ao enfatizar a necessidade de tornar a álgebra "significativa", explica que nessa etapa de ensino é preciso enfatizar o processo de generalização e que ele seja fomentado e desenvolvido de diversas formas. O documento ainda destaca o uso de gráficos e tabelas como fundamentais nesse processo. 
Os PCN anos finais (1998) mostram posicionamento quanto à álgebra nos anos iniciais do Ensino Fundamental, destacando que

Os adolescentes desenvolvem de forma bastante significativa a habilidade de pensar abstratamente, se lhes forem proporcionadas experiências variadas envolvendo noções algébricas, a partir dos ciclos iniciais, de modo informal, em um trabalho articulado com a Aritmética. Assim, os alunos adquirem base para uma aprendizagem de Álgebra mais sólida e rica em significados. Embora se considere importante que esse trabalho chamado de pré-álgebra aconteça nas séries iniciais, ele deve ser retomado no terceiro ciclo para que as noções e conceitos algébricos possam ser ampliados e consolidados (BRASIL, 1998, p. 117).

Segundo os PCN (BRASIL, 1998), nos anos iniciais do Ensino Fundamental, a álgebra pode ser desenvolvida sem uma formalização sistemática de procedimentos para resoluções de equações com a linguagem simbólica própria desse conteúdo. Os fundamentos da álgebra que precisam ser desenvolvidos nos anos iniciais, como dito anteriormente, são os processos de generalização, regularidade e equivalência. Tais processos, para os PCN, constituem a chamada pré-álgebra.

Outro aspecto que os PCN de matemática dos anos finais do Ensino Fundamental destacam é a articulação da álgebra com a aritmética. A aritmética, com seu foco nas operações, é priorizada nos anos iniciais do ensino fundamental e os documentos analisados destacam a relevância de uma prática pedagógica integrada entre a álgebra e aritmética desde os anos iniciais.

\section{Álgebra no documento "Elementos Conceituais e Metodológicos para a definição dos Direitos de Aprendizagem e desenvolvimento do Ciclo de alfabetização do Ensino Fundamental"}

Outros documentos oficiais do Ministério da Educação brasileiro apresentam especificações curriculares para os anos iniciais do Ensino Fundamental, é o caso do "Elementos Conceituais e Metodológicos para a definição dos Direitos de Aprendizagem e desenvolvimento do Ciclo de alfabetização do Ensino Fundamental" (BRASIL, 2012), que foi elaborado no contexto da política do Pacto Nacional pela Alfabetização na Idade Certa (PNAIC), um programa do Ministério da Educação, extinto em 2018, que apresentou diversas ações para alcançar a meta de alfabetizar crianças até, no máximo, oito anos de idade. 
O documento, proposto pelo Ministério da Educação brasileiro, apresenta especificações curriculares para os $1^{\circ}, 2^{\circ}$ e $3^{\circ}$ anos do Ensino Fundamental, o denominado Ciclo de Alfabetização e letramento. Ele se refere à álgebra como um eixo estruturante chamado "Pensamento algébrico", o que representa um avanço quanto ao que propunham os PCN a medida que reconhece que esse é um conhecimento que pode ser trabalhado de forma mais efetiva com as crianças, já no ciclo de alfabetização, não se configurando apenas como algo aproximado, pré-álgebra.

Relativo a esse eixo, o documento orientador do PNAIC aponta a compreensão de padrões e relações, a partir de diferentes contextos, como principal objetivo para a aprendizagem da álgebra e que compreende o alcance de três "direitos de aprendizagem"1, que circulam como objetivos mais específicos e que devem ser desenvolvidos ao longo dos três primeiros anos do Ciclo de Alfabetização.

Conforme apresentado no Quadro 1, para cada ano de ensino $\left(1^{\circ}, 2^{\circ}\right.$ e $3^{\circ}$ anos $)$ são propostos, nesse documento, os "direitos de aprendizagem" e em que ano esses devem ser iniciados (I), aprofundados (A) ou consolidados (C).

Para o primeiro ano do Ensino Fundamental, por exemplo, é preciso iniciar o seguinte objetivo "estabelecer critérios para agrupar, classificar e ordenar objetos, considerando diferentes atributos" (BRASIL, 2012, p. 77), esse direito deve ser aprofundado no $2^{\circ}$ e consolidado no $3^{\circ}$ ano. Sendo assim, o documento orientador do PNAIC apresenta, de forma mais detalhada do que nos PCN, o que pode ser priorizado nos três anos do ciclo de alfabetização e letramento (Quadro 1).

\footnotetext{
${ }^{1} \mathrm{O}$ termo "direitos de aprendizagem", segundo o Ministério de Educação brasileiro, se refere aos objetivos de aprendizagem elencados para cada área e ano de ensino. Os objetivos são assim denominados com o fim de indicar um compromisso coletivo, de modo a buscar a garantia de aprendizagens essenciais na área e ano de ensino indicados, como um direito básico da criança.
} 
Quadro 1: Objetivos de aprendizagem da álgebra no documento orientador do PNAIC

\begin{tabular}{|l|c|c|c|}
\hline \multicolumn{1}{|c|}{$\begin{array}{c}\text { Eixo estruturante pensamento algébrico - } \\
\text { Objetivos de aprendizagem }\end{array}$} & $1^{\circ}$ ano & $2^{\circ}$ ano \\
\hline \multicolumn{2}{|c|}{ Compreender padrões e relações, a partir de diferentes contextos } \\
\hline $\begin{array}{l}\text { Estabelecer critérios para agrupar, classificar e ordenar objetos, } \\
\text { considerando diferentes atributos. }\end{array}$ & I & I/A & A/C \\
\hline $\begin{array}{l}\text { Reconhecer padrões de uma sequência para identificação dos } \\
\text { próximos elementos, em sequências de sons e formas ou padrões } \\
\text { numéricos simples. }\end{array}$ & I & I/A & A/C \\
\hline $\begin{array}{l}\text { Produzir padrões em faixas decorativas, em sequências de sons e } \\
\text { formas ou padrões numéricos simples. }\end{array}$ & I & I/A & A/C \\
\hline LEGENDA: I - Introduzir; A - Aprofundar; C - Consolidar. & & \\
\hline
\end{tabular}

Fonte: BRASIL (2012, p. 77)

Considerando o exposto no Quadro 1, o documento orientador curricular do PNAIC (BRASIL, 2012) ressalta o fomento ao pensamento algébrico desde o $1^{\circ}$ ano do Ensino Fundamental e a consolidação dos três objetivos pelo aluno até o final do $3^{\circ}$ ano. Para isso, indica como foco para o trabalho pedagógico do eixo da álgebra no ciclo de alfabetização, a abordagem de padrões e sequências.

\section{A álgebra nos anos iniciais do Ensino Fundamental no documento da Base Nacional Comum Curricular}

A Base Nacional Comum Curricular - BNCC (BRASIL, 2017) passou a vigorar como documento oficial do Ministério da Educação brasileiro em 2017. Esse documento orienta o currículo para a Educação Básica nacional nos seguintes níveis de ensino: Educação Infantil, Ensino Fundamental e Ensino Médio, substituindo assim os PCN e o documento orientador do PNAIC, então extinto.

Ao longo do processo de construção da BNCC, três versões do documento foram disponibilizadas no Portal $^{2}$ destinado para consulta pública, o objetivo, segundo o MEC, era que a população pudesse sugerir, criticar e opinar acerca do conteúdo proposto na BNCC, embora não haja clareza de como as contribuições da sociedade civil foram incorporadas ao documento. Para conhecer as orientações sobre a álgebra nos anos iniciais do Ensino Fundamental, analisamos as três versões disponibilizadas on-line.

\footnotetext{
${ }^{2}$ http://basenacionalcomum.mec.gov.br
} 
A consulta pública da primeira versão foi realizada entre outubro de 2015 e março de 2016. A segunda versão foi examinada, sistematizada e reorganizada no ano de 2016. Em abril de 2017, o MEC divulga a terceira e última versão da BNCC.

A Base Nacional Comum Curricular (BNCC) é um documento de caráter normativo que define o conjunto orgânico e progressivo de aprendizagens essenciais que todos os alunos devem desenvolver ao longo das etapas e modalidades da Educação Básica. Aplica-se à educação escolar, tal como a define o $\S 1^{\circ}$ do Artigo $1^{\circ}$ da Lei de Diretrizes e Bases da Educação Nacional (LDB, Lei nº 9.394/1996), e indica conhecimentos e competências que se espera que todos os estudantes desenvolvam ao longo da escolaridade. Orientada pelos princípios éticos, políticos e estéticos traçados pelas Diretrizes Curriculares Nacionais da Educação Básica (DCN), a BNCC soma-se aos propósitos que direcionam a educação brasileira para a formação humana integral e para a construção de uma sociedade justa, democrática e inclusiva (BRASIL, 2017, p. 7).

No que se refere à Matemática nos anos iniciais do Ensino Fundamental, a BNCC apresenta alterações em relação aos PCN nas unidades temáticas de ensino, uma vez que, assim como o documento do PNAIC, traz a álgebra como uma nova unidade temática, junto com as unidades: números, geometria, grandezas e medidas, probabilidade e estatística. De acordo com as orientações da BNCC, na unidade Álgebra, o foco do $1^{\circ}$ ao $5^{\circ}$ ano do Ensino Fundamental não deve ser a formalização de regras e fórmulas e sim o desenvolvimento do pensamento algébrico, nos processos de regularidade, generalização e equivalência.

Diferentemente dos PCN, a BNCC traz de modo mais sistemático orientações sobre o ensino da álgebra nos anos iniciais do Ensino Fundamental, limitando esse ensino a um processo intuitivo de elementos da álgebra formal, como os processos de generalização, reconhecimento e estabelecimento de critérios, denominando a unidade temática de Álgebra.

Quanto ao desenvolvimento do pensamento algébrico no Ciclo de alfabetização e letramento ( $1^{\circ}, 2^{\circ}$ e $3^{\circ}$ anos do Ensino Fundamental), o foco de ensino orientado pela BNCC é a organização de sequências de figuras por atributos e cores, na organização em ordem crescente e decrescente por meio de diversas estratégias, com o fim de desenvolver a generalização e perceber regularidades. $\mathrm{O}$ documento indica o trabalho com o símbolo de igualdade desde o $3^{\circ}$ ano do Ensino Fundamental, apresentando assim, um avanço quanto ao documento do PNAIC.

Para os $4^{\circ}$ e $5^{\circ}$ anos, o foco das orientações da BNCC, com relação aos objetivos para o desenvolvimento do pensamento algébrico, encontra-se nas noções de equivalência, nas 
habilidades de identificação de termos desconhecidos e no uso das quatro operações matemáticas para resolver e elaborar situações-problema algébricos.

A BNCC organiza e apresenta suas orientações curriculares por meio da exposição de habilidades a serem asseguradas aos alunos em cada ano de estudo. Todas as áreas de ensino possuem as suas unidades temáticas, ou eixos, que se estruturam em torno de habilidades cognitivas que se relacionam a objetos de conhecimento - conteúdos, conceitos e processos (BRASIL, 2017, p. 26).

Para o $4^{\circ}$ ano, a Base Nacional Comum Curricular orienta, quanto a unidade da álgebra, a utilização da adição, subtração, divisão e multiplicação, seja para perceber regularidades dos múltiplos numa sequência, numa divisão com restos iguais ou ainda reconhecer as relações inversas da adição e subtração e multiplicação e divisão, com o uso de calculadoras e situaçõesproblema. Ainda neste ano, a Base sugere o reconhecimento das propriedades de igualdade, ou seja, que uma igualdade permanece a mesma quando se adiciona ou se subtrai uma mesma quantidade aos seus dois termos. Dentro da competência das propriedades da igualdade, o documento orienta, ainda para o $4^{\circ}$ ano, o trabalho com o número desconhecido por meio de desafios e situações-problema com números naturais.

Para o $5^{\circ}$ ano do Ensino Fundamental, a Base propõe que seja dada continuidade às noções de igualdade e de equivalência, elaboração e resolução de situações-problema e ainda a introdução à ideia multiplicativa da proporcionalidade.

\section{A álgebra nos anos iniciais do Ensino Fundamental: abordagens científicas}

Conforme já mencionado, o levantamento bibliográfico realizado com o objetivo de inventariar pesquisas desenvolvidas sobre o ensino e aprendizagem de álgebra nos anos iniciais do Ensino Fundamental consistiu na análise de trabalhos publicados nos anais do Encontro Nacional de Educação Matemática (ENEM).

A partir dos textos identificados nessas fontes, ocupamo-nos em realizar um mapeamento sobre o quê se discute academicamente sobre a álgebra nos anos iniciais, como se discute e quem discute, de modo que as informações coletadas permitiram uma breve noção sobre os alcances dessas pesquisas em relação ao tema, possibilitando uma visão situacional para o desenvolvimento de novas pesquisas. 
O ensino de álgebra nos anos iniciais do Ensino Fundamental...

Optamos por pesquisar nos anais ${ }^{3}$ do Encontro Nacional de Educação Matemática (ENEM), uma vez que esse evento científico é um dos maiores da área de Educação Matemática vinculados a Sociedade Brasileira de Educação Matemática (SBEM) e realizados no Brasil. O evento congrega um público amplo, que inclui professores da Educação Básica, professores e estudantes das Licenciaturas em Matemática e em Pedagogia, estudantes da Pós-graduação e pesquisadores. A cada encontro constatamos o interesse pelas discussões sobre a Educação Matemática, seus fazeres múltiplos e complexos, tendências metodológicas e pesquisas que constituem a área.

O I ENEM aconteceu em 1987 e até 2016 foram realizadas doze edições desse evento que, atualmente, ocorre com frequência trienal. O levantamento de dados ora apresentado compreendeu as doze edições ate então ocorridas e também foi realizado com o objetivo de adquirirmos uma visão global sobre a quantidade e o conteúdo dos trabalhos acerca da álgebra nos anos iniciais do Ensino Fundamental. Além disso, permitiu-nos explorar pontos mais específicos, como os referenciais teóricos mais utilizados, estratégias para a análise de dados, objetivos gerais e específicos que nortearam os trabalhos e o público alvo abrangido pelas pesquisas.

É importante explicarmos que os anais do Encontro Nacional de Educação Matemática disponibilizam, da primeira à sétima edição, apenas o título dos trabalhos e/ou o resumo e, da oitava à décima segunda edição do ENEM, os trabalhos completos tornam-se acessíveis ao público. Sendo assim, ao identificarmos uma pesquisa relativa ao tema, realizamos a leitura investigativa a fim de saber $o$ que foi pesquisado, como e por quem foi desenvolvido o estudo.

Cada edição do evento tinha um perfil diferente na exposição dos anais, os primeiros não tinham site, a página da SBEM apenas digitalizou o caderno de anais até a sétima edição. Da oitava a décima segunda edição do evento, por exemplo, encontramos alguns sites e constatamos, especialmente em notas da comissão de organização das respectivas edições, que os trabalhos eram organizados de forma diferente em cada uma dessas, uns separavam as pesquisas por temas, outros apenas pela modalidade de apresentação (pôster, comunicação científica, palestra).

\footnotetext{
${ }^{3}$ Os anais de todas as edições encontram-se no seguinte endereço eletrônico:

<http://www.sbembrasil.org.br/sbembrasil/index.php/anais/enem> Acesso em 02 abr. 2017.
} 
Iniciamos, então, nossa busca nos anais do I ENEM, o evento aconteceu em 1987 na Pontifícia Universidade Católica de São Paulo. Primeiramente, fizemos uma leitura do índice dos anais no site, a fim de verificar se havia algum trabalho que tratasse sobre a álgebra nos anos iniciais. Pela leitura dos títulos, não identificamos ocorrências, apenas um minicurso tratava sobre a álgebra, mas com foco no ensino médio.

Os anais do I ENEM não apresentam os títulos das sessões coordenadas, mesas redondas e outras modalidades, exibem apenas as discussões, conclusões e recomendações suscitadas em cada sessão. Na análise do conteúdo desse material não identificamos publicações referentes ao ensino e aprendizagem da álgebra nos anos iniciais do Ensino Fundamental.

Quanto ao II ENEM, que ocorreu em 1988, na Universidade Estadual de Maringá, Paraná, iniciamos a pesquisa no caderno de resumos, pela leitura dos títulos das comunicações apresentadas nas exposições e das mesas redondas. Não localizamos pesquisas que se vinculem especificamente à álgebra nos anos iniciais. Contudo, os anais do II ENEM apresentam o resumo dos trabalhos, o que nos permitiu buscar aqueles que tratavam sobre temáticas que envolvem a álgebra relacionada ao ensino com crianças. Um dos trabalhos, da categoria comunicações científicas, intitulado "Ensino de equações: uma tentativa do emprego de um método de ensino ativo", tratou sobre as equações e explicita no resumo que "foi apresentado às crianças uma série de problemas concretos, na forma de jogos para se chegar a elaboração da sentença matemática" (SOUZA JÚNIOR, 1988, p. 54), o que nos permitiu inferir que tal comunicação trata sobre o ensino e aprendizagem da álgebra com crianças. A partir desse ocorrido, ressaltamos a importância da leitura dos resumos e não apenas do título dos trabalhos para o estado da arte. Os minicursos não apresentaram temáticas relacionadas ao nosso foco de estudo.

Nos anais da terceira edição do evento, ocorrido em 1990, na Universidade Federal do Rio Grande do Norte, identificamos dois minicursos relacionados à álgebra com crianças. $\mathrm{O}$ primeiro com o título "O ensino da álgebra: conteúdo e forma" (LOPES, 1990, p. 21) problematizou o conteúdo e forma do ensino da álgebra desde a $5^{\mathrm{a}}$ série (atual $6^{\circ}$ ano do Ensino Fundamental). O minicurso apresentou uma proposta de ensino e aprendizagem da álgebra de forma lúdica, com jogos matemáticos, materiais manipuláveis e modelagem.

O segundo minicurso, intitulado "Introdução à álgebra" (VIANNA, 1990, p. 37), voltado para professores das então $1^{\mathrm{a}}$ a $8^{\mathrm{a}}$ séries que, atualmente, corresponde ao período do $2^{\mathrm{o}}$ ao $9^{\circ}$ ano do Ensino Fundamental. Teve como objetivo explicitar uma proposta de ensino e aprendizagem 
das noções iniciais do conteúdo algébrico. Não localizamos trabalhos de outra categoria científica que tratassem do tema buscado.

Não localizamos trabalhos específicos sobre nosso tema na quarta edição do ENEM, ocorrida em 1992, na Universidade Regional de Blumenau, em Blumenau, em Santa Catarina.

No V ENEM, ocorrido em 1995, na Universidade Federal de Sergipe, encontramos apenas uma comunicação científica (FARIAS; BARBOSA; DIAS, 1995), que aponta a relevância de um ensino significativo da álgebra desde a infância. O trabalho destaca que a dificuldade dos alunos quanto à álgebra é consequência de um ensino formal, com ênfase nos procedimentos e algoritmos e não no significado das operações.

O VI ENEM aconteceu em 1998, na Universidade do Vale do Rio dos Sinos, em São Leopoldo, Rio Grande do Sul. Identificamos nos anais dessa edição o minicurso "Pensando algebricamente antes da $7^{\text {a }}$ série" (OLIVEIRA, 1998), que fomenta a reflexão sobre a necessidade de introduzir conceitos algébricos desde os anos iniciais do Ensino Fundamental. O resumo explicita que o objetivo do trabalho é investigar como os alunos da $5^{\mathrm{a}}$ série, atual $6^{\circ}$ ano do Ensino Fundamental, desenvolvem o pensamento algébrico. A proposta do minicurso foi de discutir e problematizar a necessidade da introdução da álgebra antes da $5^{\mathrm{a}}$ série (atual $6^{\circ}$ ano), ou seja, em turmas com crianças que atualmente compõem os anos iniciais do Ensino Fundamental.

É importante destacarmos que ao fazermos a leitura dos títulos e identificarmos a palavra-chave álgebra, lemos o resumo (quando disponibilizado), mesmo que não tratasse especificamente sobre o ensino e aprendizagem da álgebra nos anos iniciais do Ensino Fundamental. Essa leitura investigativa nos levava a perceber alguns pontos específicos sobre os conteúdos, abordagens, metodologias, principais dificuldades dos docentes e discentes. Uma delas, como destacado anteriormente, é a relação que os pesquisadores apontaram entre a álgebra e a geometria como estratégia para tornar o ensino e a aprendizagem da álgebra mais significativos.

Nas comunicações orais, o VI ENEM ofereceu um bloco temático sobre educação algébrica. Dos treze trabalhos apresentados, pela leitura do título selecionamos apenas duas comunicações científicas, porém, ao lermos o resumo, apenas uma tratava sobre a álgebra com crianças (LIMA; FALCÃO, 1998). Na investigação, os autores abordaram a relevância do 
enfoque aritmética-álgebra como um continuum na introdução de problemas algébricos com crianças a partir de seis anos de idade.

O VII ENEM aconteceu na Universidade Federal do Rio de Janeiro, em 2001. Dos títulos que apresentavam a palavra-chave álgebra, nenhum trabalho tratava sobre o ensino e aprendizagem nos anos iniciais do Ensino Fundamental. Partimos então para a busca de trabalho na oitava edição do evento.

O VIII Encontro Nacional de Educação Matemática ocorreu em Recife, no ano de 2004. Da oitava edição, analisamos apenas o grupo de trabalho voltado para os anos iniciais do Ensino Fundamental, no qual identificamos uma comunicação científica intitulada "Lógico-histórico: uma perspectiva para o ensino da álgebra" (MOURA; SOUSA, 2004), cujas autoras também ministraram um minicurso sobre a mesma temática. Com a leitura dos trabalhos desse GT, identificamos que os autores apresentaram uma visão filosófica acerca da álgebra. Embora inseridos no GT dos anos iniciais, as conclusões desses trabalhos aplicam-se a qualquer nível de ensino, pois problematizam a abstração da álgebra e tratam sobre a necessidade de (re)significar o seu ensino a partir da realidade dos alunos.

Em 2007, o IX ENEM aconteceu na Universidade de Belo Horizonte, em Belo Horizonte, Minas Gerais. Dentre as comunicações científicas, localizamos a de Freire e Filho (2007). O texto apresenta uma pesquisa de mestrado, na época, em andamento, que realizou atividades para desenvolver, intuitivamente, os conceitos de incógnita, equivalência, igualdade e desigualdade com alunos do $3^{\circ}$ ano e $5^{\circ}$ ano do Ensino Fundamental. Os pesquisadores responsáveis pelo trabalho fizeram uso do método clínico piagetiano, com perguntas que se modificam de acordo com as respostas dos participantes. A pesquisa utilizou uma balança interativa de dois pratos que, como um jogo, tinha o objetivo de fazer com que os alunos descobrissem o peso desconhecido para equilibrar a balança. A análise se focou não no desempenho dos estudantes, mas nas estratégias de resolução das situações-problema.

O X ENEM ocorreu em Salvador, no ano de 2010. O site do X ENEM organizou os anais por eixos temáticos, dos quais investigamos apenas dois, que são: ensino e aprendizagem em álgebra e Educação Matemática nos anos iniciais. No primeiro eixo, encontramos apenas o trabalho de Porto at al. (2010), que se configura como um relato de experiência. O texto apresenta uma experiência realizada com duas turmas do $1^{\circ}$ ano do Ensino Fundamental. As atividades desenvolvidas se focaram em desafios para que as crianças vivenciassem situações 
de fomento à álgebra. No segundo eixo, por sua vez, não foi encontrado trabalho com a temática de nosso interesse.

O XI ENEM, ocorrido na Pontifícia Universidade Católica do Paraná, em Curitiba, aconteceu no ano de 2013. No site do XI ENEM, pesquisamos por eixo temático, os eixos escolhidos foram: formação de professores, pesquisa em educação matemática e práticas escolares.

Identificamos um relato de experiência no eixo práticas escolares, que tratou sobre a forma lúdica de desenvolver o pensamento algébrico, de Oliveira e Silva (2013). O texto relata a experiência de um Clube da matemática, realizado com alunos do Ensino Fundamental em uma escola pública e destaca a aprendizagem por meio de tarefas lúdicas como jogos e brincadeiras. De acordo com os autores, os alunos precisam compreender o processo de construção das ideias matemáticas e não apenas decorar procedimentos. Dessa forma, os estudantes participavam uma vez por semana do Clube da Matemática, as tarefas desenvolviam o conceito de função, representações simbólicas e ideias intrínsecas ao conceito de equação.

Na modalidade Pôster, localizamos a publicação de Boni, Ferreira e Germano (2013) que teve como base as atividades do programa Early álgebra ${ }^{4}$, posto que professores do Ensino Fundamental resolveram e adaptaram as situações-problema com ênfase na interpretação e compreensão de símbolos. Outro trabalho na modalidade pôster, identificado no eixo formação de professores (PIRES; DARIVA, 2013) explica o que é álgebra, o que significa pensamento algébrico e enfatiza que nos anos iniciais é preciso que os alunos compreendam os símbolos, identifiquem generalizações e construam regras a partir dessa percepção.

O XII ENEM aconteceu no ano de 2016, na Universidade Cruzeiro do Sul, em São Paulo. Em seus anais identificamos apenas duas comunicações científicas de nosso interesse, intituladas "Indícios de generalização da linguagem algébrica simbólica por estudantes do clube de matemática" (OLIVEIRA; CEDRO, 2016) e "Um mapeamento de teses e dissertações que abordam o ensino e a aprendizagem da álgebra no ensino fundamental no Brasil" (RODRIGUES, 2016).

O primeiro objetiva apresentar indícios de generalização da linguagem algébrica. Os autores realizaram atividades dentro de um Clube da Matemática com doze crianças do Ensino

\footnotetext{
${ }^{4}$ http://ase.tufts.edu/education/earlyalgebra/about.asp
} 
Fundamental, em uma escola municipal de Goiânia. Os pesquisadores utilizaram o registro escrito, oral, gravações audiovisuais, rodas de conversa e diário de campo dos pesquisadores como instrumentos de análise. As tarefas objetivavam que as crianças percebessem a necessidade de compreender a linguagem algébrica no cotidiano e dos conceitos de equivalência e variável de forma lúdica, com trilha, boliche, ludo e outros jogos e brincadeiras.

O segundo, uma comunicação científica, aborda o ensino e a aprendizagem da álgebra no ensino fundamental no Brasil (RODRIGUES, 2016). O trabalho apresentou o resultado de uma pesquisa que objetivou apresentar o Estado da Arte no Portal de Periódicos da CAPES sobre a álgebra nos anos iniciais do Ensino Fundamental. Os resultados da investigação remetem a uma carência de trabalhos com a temática voltada para os primeiros ciclos do Ensino Fundamental, pois a maior parte das pesquisas identificadas possuíam como foco os anos finais e o ensino médio.

$\mathrm{Na}$ modalidade de relato de experiência, identificamos um trabalho intitulado "Mapeamento de trabalhos sobre pensamento algébrico nos anos iniciais apresentados nos ENEM (1998 - 2013)" - (LIMA, 2016). A pesquisa analisou os anais do VI ao XI ENEM, enquanto a nossa investigação foi realizada nos anais do I ENEM ao XII ENEM. O estudo de Lima (2016), assim como o nosso, assinala poucas recorrências de pesquisas sobre o pensamento algébrico nos anos iniciais no Encontro Nacional de Educação Matemática. O autor ainda aponta a importância de levantamentos de Estado da Arte em eventos como o ENEM, visto que, além de conhecer globalmente os estudos apresentados no evento, possibilita a identificação de lacunas, convergências e divergências dos trabalhos dentro de uma mesma temática.

O pesquisador destacou o papel da álgebra no desenvolvimento do raciocínio lógicomatemático. Além disso, assim como nós, refletiu sobre o destaque dado nos novos documentos oficiais acerca da álgebra para crianças, como o documento da Base Nacional Comum Curricular e o orientador dos direitos de aprendizagem do ciclo de alfabetização.

$\mathrm{Na}$ modalidade de minicurso, identificamos um trabalho que trata sobre a álgebra nos anos iniciais do Ensino Fundamental, intitulado "O pensamento algébrico nos anos iniciais do ensino fundamental" (SANTOS; MOREIRA, 2016). O texto apresenta seis tarefas realizadas com alunos dos anos iniciais do Ensino Fundamental, o trabalho possibilitou a reflexão sobre as 
O ensino de álgebra nos anos iniciais do Ensino Fundamental...

diferentes estratégias possíveis para desenvolver o ensino e aprendizagem da álgebra, dentre elas o uso de tarefas com foco na identificação de regularidades.

Ao finalizarmos a análise dos anais do ENEM, concluímos que o levantamento evidencia que as pesquisas concentram suas intervenções com foco na identificação de padrões e regularidades e as tarefas são baseadas em abordagens lúdicas, como jogos e brincadeiras e situações-problema. Em suas discussões, os trabalhos relacionam a álgebra com os conteúdos de geometria e aritmética.

\section{Considerações finais}

Em suma, a leitura e a análise dos documentos apresentados nesse artigo possibilitaramnos conhecer pontos convergentes e divergentes quanto ao ensino e a aprendizagem da álgebra presentes nos documentos oficiais de orientações curriculares para os anos iniciais do Ensino Fundamental. Como convergência, destacamos a ênfase que os documentos apresentam quanto ao processo de generalização; e a necessidade de fomentar o pensamento algébrico na infância. Alguns apresentam exemplos e orientações mais específicas, como a BNCC, que embora apresentam os objetos de aprendizagem, ainda são restritos quanto às possibilidades de abordagem desses conteúdos; outros, por sua vez, citam a álgebra de modo superficial, não deixando claro os objetivos de aprendizagem e sem de fato orientar e apresentar orientações pedagógicas para o ensino da álgebra na infância, como os PCN de matemática dos anos iniciais do Ensino Fundamental. O documento que especifica com maior clareza o que deve ser objetivado no trabalho com a álgebra é a Base Nacional Comum Curricular, que apresenta objetos de aprendizagem desde o Ciclo de alfabetização.

Após a consulta nos documentos, realizamos o levantamento bibliográfico nos anais de doze edições do Encontro Nacional de Educação Matemática (ENEM) que, por sua vez, sinaliza para uma produção restrita sobre o assunto. As pesquisas concentram suas intervenções em tarefas baseadas em atividades lúdicas, como jogos e brincadeiras e situações-problemas, que relacionam a álgebra com os conteúdos da geometria e da aritmética. Nos trabalhos analisados, as atividades propostas para os alunos são organizadas da seguinte forma: em grupos e após a realização da tarefa, seguidas de um momento de discussão e retomada das atividades executadas.

Além disso, observou-se que, em sua maioria, as pesquisas que abordam a álgebra com crianças tratam sobre o trabalho com padrões e sequências e pouco abordam a ideia de 
equivalência e o símbolo de igualdade em turmas de $3^{\circ}, 4^{\circ}$ e $5^{\circ}$ ano, conforme orientado na BNCC.

Por fim, concluímos que o campo da álgebra necessita ser mais explorado, investigado e compreendido no âmbito dos anos iniciais do Ensino Fundamental, principalmente após a aprovação da BNCC, que orienta um trabalho sistemático com a álgebra desde o $1^{\circ}$ ano do Ensino Fundamental.

\section{Referências}

BONI, Keila Tatiana; FERREIRA, Marcia Praisler Pereira; GERMANO, Mara Aparecida Pedrini. Caracterização do pensamento algébrico nos anos iniciais. In: Encontro Nacional de Educação Matemática, 11., Curitiba, Anais... Curitiba: SBEM-PR, 2013. Disponível em: http://sbem.iuri0094.hospedagemdesites.ws/anais/XIENEM/pdf/2538 2056 ID.pdf Acesso em: 10 mai. 2017.

BRASIL, Constituição da República Federativa do Brasil, Brasília, DF: Senado Federal: Centro Gráfico, 1988. Disponível em: <http://www.planalto.gov.br/ccivil_03/constituicao/constituicao.htm> Acesso em: 01 mai. 2017.

BRASIL, Ministério da Educação. Secretaria de Educação Básica. Diretoria de Currículos e Educação Integral - DICEI. Coordenação Geral do Ensino Fundamental - COEF. Elementos conceituais e metodológicos para definição dos direitos de aprendizagem $e$ desenvolvimento do ciclo básico de alfabetização $\left(1^{\circ}, 2^{\circ}\right.$ e $3^{\circ}$ anos $)$ do ensino fundamental. Brasília, F: MEC, 2012.

BRASIL, Secretaria de Ensino Fundamental. Parâmetros Curriculares Nacionais: matemática. Secretaria de Educação Fundamental. Brasília: MEC/SEF, 1997. Disponível em: <http://portal.mec.gov.br/seb/arquivos/pdf/livro03.pdf> Acesso em: 01 mai. 2017.

BRASIL, Secretaria de Ensino Fundamental. Parâmetros Curriculares Nacionais: matemática. Secretaria de Educação Fundamental. Brasília: MEC/SEF, 1998. Disponível em: <http://portal.mec.gov.br/seb/arquivos/pdf/matematica.pdf> Acesso em: 01 mai. 2017.

BRASIL. Ministério da Educação. Base Nacional Comum Curricular. Terceira versão revista. Brasília: MEC, 2017. Disponível em: <http://basenacionalcomum.mec.gov.br > Acesso em: 01 dez. 2017.

BRASIL. Ministério de Educação e Cultura. LDB - Lei $n^{\circ}$ 9394/96, de 20 de dezembro de 1996. Estabelece as diretrizes e bases da Educação Nacional. Brasília: MEC, 1996. Disponível em: <http:// www.planalto.gov.br/ccivil_03/leis/L9394.htm> Acesso em: 01 mai. 2017

CURY, Carlos Roberto Jamil; REIS, Magali; ZANARDI, Teodoro Adriano Costa. Base Nacional Comum Curricular: dilemas e perspectivas. São Paulo: Cortez, 2018. 
CYRINO, Márcia Cristina de Costa Trindade; Oliveira, Hélia Margarida de. Pensamento Algébrico ao longo do Ensino Básico em Portugal. Bolema, Rio Claro (SP), v. 24, $\mathrm{n}^{\mathrm{o}}$ 38, p. 97 a 126, abril 2011. Disponível em: <http://www.redalyc.org/pdf/2912/291222086006.pdf> Acesso em: 23 fev. 2017.

FARIAS, José Moacir Vasconcelos; BARBOSA, Gerardo Oliveira; DIAS, Ana Maria Iório. Propriedades das operações fundamentais na passagem da aritmética para a álgebra. In: Encontro Nacional de Educação Matemática, 5., 1995, Aracaju, Anais... Aracaju: SBEM/SE, 1995, p. 209-210. Disponível em: <http://www.sbembrasil.org.br/sbembrasil/index.php/anais/enem> Acesso em: 02 abr. 2017.

FREIRE, Raquel Santiago; FILHO, José Aires de Castro. Crianças de séries iniciais pensando em álgebra: uma comparação entre o uso de ambientes computacionais e manipulativos. In: Encontro Nacional de Educação Matemática, 9., Belo Horizonte, Anais... Belo Horizonte: SBEM-MG, 2007. Disponível em $<$ http://sbem.iuri0094.hospedagemdesites.ws/anais/ix_enem/Comunicacao_Cientific a/Trabalhos/CC90480732353T.doc> Acesso em: 25 abr 2017.

LAVILLE, Christian; DIONNE, Jean. A construção do saber: manual de metodologia da pesquisa em Ciências Humanas. Porto Alegre: Artmed; Belo Horizonte: Editora UFMG, 1999.

LIMA, Anna Paula Brito; FALCÃO, Jorge Tarcísio da Rocha. Desenvolvimento da representação algébrica em crianças de $1^{a}$. A $6^{a}$. série do $1^{o}$ Grau. In: Encontro Nacional de Educação Matemática, 6. São Leopoldo, Anais... São Leopoldo, 1998, p. 510-512. <http://www.sbembrasil.org.br/sbembrasil/index.php/anais/enem> Acesso em: 02 abr 2017.

LIMA, José Roberto de Campos. Mapeamento de trabalhos sobre pensamento algébrico nos anos iniciais apresentados nos ENEM (1998 - 2013). In: Encontro Nacional de Educação Matemática, 12., São Paulo, Anais... São Paulo: SBEM-SP, 2016.

Disponível

em: <http://www.sbembrasil.org.br/enem2016/anais/pdf/7327_4156_ID.pdf> Acesso em: 10 mai. 2017.

LOPES, Antônio José. O ensino da álgebra: conteúdo e forma. In: Encontro Nacional de Educação Matemática, 3., 1990, Natal, Anais... Natal: UFRN Editora Universitária, 1990, p. $29 . \quad$ Disponível em: <http://www.sbembrasil.org.br/sbembrasil/index.php/anais/enem> Acesso em: 02 abr. 2017.

LUNA, Ana Virgínia de Almeida; SOUZA, Cremilzza Carla Carneiro Ferreira. Discussões sobre o ensino de álgebra nos anos iniciais do Ensino Fundamental. Educação Matemática Pesquisa, São Paulo, v.15, Número Especial, 2013, p.817-835. Disponível em: <https://revistas.pucsp.br/emp/article/view/17747/pdf_1> Acesso em: 14 jul. 2019.

MOURA, Anna Regina Lanner; SOUSA, Maria do Carmo de. Lógico-histórico: uma perspectiva para o ensino da álgebra. In: Encontro Nacional de Educação Matemática, 8., Recife, Anais... Recife: SBEM-PE, 2004. Disponível em: <http://www.sbembrasil.org.br/files/viii/arquivos/index_1.htm> Acesso em: 25 abr 2017. 
NATIONAL COUNCIL OF TEACHERS OF MATHEMATICS. Princípios e normas para a matemática escolar (tradução portuguesa). Lisboa: APM, 2007.

OLIVEIRA, Daniela Cristina de; SILVA, Douglas Aires da. Clube da matemática: atividades lúdicas para o ensino de álgebra. In: Encontro Nacional de Educação Matemática, 11., Curitiba, Anais... Curitiba: SBEM-PR, 2013. Disponível em: <http://sbem.iuri0094.hospedagemdesites.ws/anais/XIENEM/pdf/68_464_ID.pdf> Acesso em: 10 mai. 2017.

OLIVEIRA, Daniela Cristina; CEDRO, Wellington. Indícios de generalização da linguagem algébrica simbólica por estudantes do clube de matemática. In: Encontro Nacional de Educação Matemática, 12., São Paulo, Anais... São Paulo: SBEM-SP, $2016 . \quad$ Disponível em: <http://www.sbembrasil.org.br/enem2016/anais/pdf/4677_2381_ID.pdf> Acesso em: 10 mai. 2017.

OLIVEIRA, Rosana. Pensando algebricamente antes $7^{a}$ série. In: Encontro Nacional de Educação Matemática, 6. São Leopoldo, Anais... São Leopoldo, 1998, p. 340-341. <http://www.sbembrasil.org.br/sbembrasil/index.php/anais/enem> Acesso em: 02 abr. 2017.

PIRES, Magna Natália Marin; DARIVA, Mirian Aparecida Montanholi; PRESTES, Diego Barboza. $O$ desenvolvimento do pensamento algébrico com crianças dos anos iniciais. In: Encontro Nacional de Educação Matemática, 11., Curitiba, Anais... Curitiba: SBEM-PR, 2013. Disponível em: <http://sbem.iuri0094.hospedagemdesites.ws/anais/XIENEM/pdf/2325_1834_ID.pdf> Acesso em: 10 mai. 2017.

PORTO, Mariana Lima et al. Construindo a base do pensamento algébrico com crianças de 6 anos. In: X Encontro Nacional de Educação Matemática, 9., Salvador, Anais... Salvador: $\quad$ SBEM-BA, 2010. Disponível em: <http://www.lematec.net.br/CDS/ENEM10/?info_type=processsel\&lang_user=> Acesso em: 28 abr. 2017.

RODRIGUES, Ivan Cruz. Um mapeamento de teses e dissertações que abordam $o$ ensino e a aprendizagem da álgebra no ensino fundamental no Brasil. In: Encontro Nacional de Educação Matemática, 12., São Paulo, Anais... São Paulo: SBEM-SP, 2016. Disponível em: <http://www.sbembrasil.org.br/enem2016/anais/pdf/5669_3295_ID.pdf> Acesso em: 10 mai. 2017.

ROMANOWSKI, Joana Paulin; ENS, Romilda Teodora. As pesquisas denominadas do tipo "estado da arte" em educação. Diálogo Educ., Curitiba, v. 6, n.19, p.37-50, set./dez. $2006 . \quad$ Disponível em: <http://www2.pucpr.br/reol/pb/index.php/dialogo?dd1=237\&dd99=view\&dd98> Acesso em: 02 mar. 2017.

SÁ-SILVA, Jackson Ronie; ALMEIDA, Cristóvão Domingos de; GUINDANI, Joel Felipe. Pesquisa documental: pistas teóricas e metodológicas. Revista Brasileira de História \& Ciências Sociais, a. 1, n. 1, jul. 2009. 
SANTOS, Carla Cristiane Silva; MOREIRA, Kátia Gabriela. O pensamento algébrico nos anos iniciais do ensino fundamental. In: Encontro Nacional de Educação Matemática, 12., São Paulo, Anais... São Paulo: SBEM-SP, 2016. Disponível em: <http://www.sbembrasil.org.br/enem2016/anais/pdf/4980_2866_ID.pdf> Acesso em: 10 mai. 2017.

SILVA, Daniele Peres da; SAVIOLI, Angela Marta Pereira das Dores. Caracterizações do pensamento algébrico em tarefas realizadas por estudantes do ensino fundamental I. Revista Eletrônica de Educação, v. 6, n. 1, mai. 2012. Disponível em: <http://www.reveduc.ufscar.br/index.php/reveduc/article/view/387/172> Acesso em: 22 fev. 2017.

SOUZA JÚNIOR, Arlindo José de Souza. Ensino de equações: uma tentativa do emprego de um método de ensino ativo. In: Encontro Nacional de Educação Matemática, 2., 1988, Maringá. Anais... Maringá, 1988, p. 54. Disponível em: <http://www.sbembrasil.org.br/sbembrasil/index.php/anais/enem> Acesso em: 02 abr. 2017.

TEIXEIRA, Célia Regina. $O$ Estado da arte: a concepção de avaliação educacional veiculada na produção acadêmica do Programa de Pós-Graduação em Educação: Currículo (1975-2000). In: Cadernos de Pós-Graduação - educação, São Paulo, v. 5, n. 1, 2006, p. 59-66.

VIANNA, Carlos Roberto. Introdução à álgebra. In: Encontro Nacional de Educação Matemática, 3., 1990, Natal, Anais... Natal: UFRN Editora Universitária, 1990, p. 37. Disponível em: <http://www.sbembrasil.org.br/sbembrasil/index.php/anais/enem> Acesso em: 02 abr. 2017. 